\title{
Planetary Gearbox Prototype Development and Manufacturing
}

\author{
Jasmin Smajic, Isad Saric, Adil Muminovic, Muamer Delic, Adis J. Muminovic*
}

\begin{abstract}
Goal of this research was to develop and manufacture planetary gearbox prototype using rapid prototyping technology (additive manufacturing). Developed prototype was used to visually analyse the design of the planetary gearbox. Also, it was used to improve and innovate education of students on several courses at Mechanical Design study program at Faculty of Mechanical Engineering. It is shown that low cost rapid prototyping technology can be used to manufacture prototypes of complex machines and machine elements. Prototypes manufactured using this technology have same functionality like the real one. Main limitation is the fact that they cannot sustain real world loads and stresses. This paper shows opportunities which low cost rapid prototyping technology is offering in improvement and innovation of education process at engineering schools and faculties. All complex and heavy machines can be manufactured using this type of technology and on that way more precisely presented to the students.
\end{abstract}

Keywords: education; mechanical design; planetary gearbox; rapid prototyping

\section{INTRODUCTION}

When professors at mechanical design courses, like machine elements, wants to present working principles, for some type of machine, they do it on one of the following ways. They can show some drawings and pictures, they can show some videos, or they can go with students to factories or laboratories where those machines can be found. This is possible only if professor has small number of students. He cannot bring one hundred students to the factory just to show them one or two machines and repeat that process for every class. It would be the best if professor can bring some of those machines to the classroom. Unfortunately, this is not possible because, usually, those machines are too heavy. Best examples are gears transmission drives, planetary gearboxes, couplings and brakes. This research is carried out to find out is it possible to use low cost rapid prototyping to manufacture above mentioned machines using lightweight polymer materials. Machines manufactured using this technology will have functionality like the real one and they will be light enough for professors to bring them to the classroom. Planetary gearbox machine is chosen for this research. This area of research is in focus right now because it is important to enable students to feel the parts and assembly in their hands. Research about enhancing the teaching of machine design by creating a basic hands-on environment with mechanical 'breadboards' was done in paper [1]. Similar research can be found in paper [2]. Goal of the research was to improve the mechanical design education introducing hands-on experience with machine parts. Research about development of machine part exhibition and functional mock-ups to enrich design education was carried out in paper [3]. Similar research was done at machine design courses at the United States Air Force Academy and at the University of Texas in Austin in USA in paper [4]. As early mentioned, planetary gearbox is chosen as case study for this research. Today, planetary gearboxes are used in many places where power and torque transmission are needed. Especially in mobile mechanical systems like cars, planes and bouts [5]. Planetary gearboxes are different in comparison to standard gears gearboxes. Main difference is in fact that standard gears gearbox has all shafts loaded in one housing and all shafts are rotating only around their own axes. Planetary gearbox has at least one shaft which is loaded in rotating element. That shaft is rotating around his own axis and around one additional axis [6].

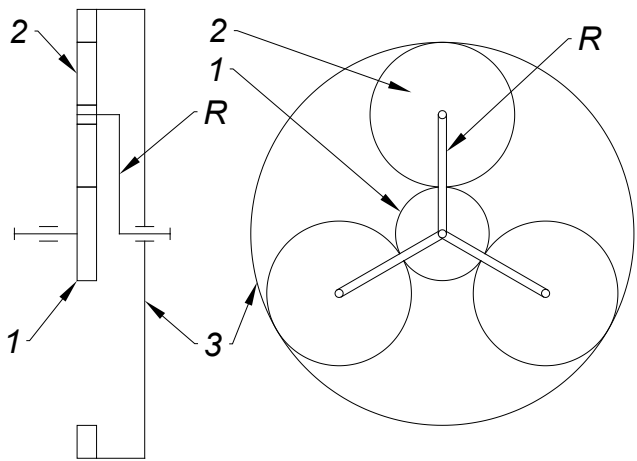

Figure 1 Basic principles of planetary gearbox

Planetary gearboxes remained in focus of research in last few years. Simulation of different types of planetary gearbox was carried out in papers [6-8]. Power loss and efficiency were studied in several research papers and doctoral dissertations. The power loss and efficiency model of a planetary gear transmission system was built with a system modelling method in paper [9]. The method takes number of different transmission elements such as gear, planetary gear sets, hydraulic torque converter, friction disk, lubrication, sealing, bump and motor into consideration and calculates non-load and load power loss for each element. The overall calculated power loss and efficiency are more accurate than the meshing power method. To make simulation more reliable it is compared with the test data [9]. Designing a transmission with goal to maximize efficiency, while keeping operating safety factors in proper boundaries is done in doctoral dissertation [10]. The main purpose of this dissertation was to study the influence of operating conditions and gear oil formulation in the efficiency of meshing gears (applied to a planetary gearbox) including elastic and dynamic effects. Vibrations of planetary 
gearboxes are studied in several papers. Planetary gearboxes excite highly modulated vibration. From the existing literature, contradicting descriptions can be obtained. In order to resolve this situation, six commodity gearboxes are investigated on a test rig. A simple, yet powerful method to extract their vibration signatures is proposed in paper [11]. Paper [12] deals with description of a diagnostic device used at the Department of Design and Machine Elements at the University of Zilina which has been built in order to measure, diagnose and evaluate gearbox faults by vibrodiagnostics. Paper [12] describes methods and damage creation process for tested gearboxes. Evaluation of different faults is also processed in paper [12] as well as description of comparative measurements between real and artificially created pitting. Comparison of all measured data with SPM methods is also included.

\subsection{Rapid Prototyping}

Rapid prototyping technologies are in the focus of research for many authors these days. One of the main manufacturing technology for rapid prototyping is additive manufacturing, especially fused deposition modelling (FDM), which is used in this research for manufacturing of planetary gearbox prototype. Machines for FDM have low cost and they become available for regular people out of the universities and big companies. Detail reviews about rapid prototyping and additive manufacturing can be found in papers $[13,14]$. By advancing of additive manufacturing technology, a lot of new questions, challenges and applications emerges. Additive manufacturing technology enables design of machine elements with less mass but in the same time with same stiffness and stress loading capacity. Example of these principals which are used for gears innovative design and manufacturing are shown in paper [15]. Also there are other papers and research about usage of rapid prototyping for gears manufacturing. Main goal of paper [16] was to establish optimal additive manufacturing parameters (printing direction, layer height and percent of infill) which will allow printed gears to replace failed steel gears, for at least some time, enough for spare steel gears to be produced and delivered on site. Special type of polymer material was developed for production of gears using rapid prototyping in paper [17]. Recent developments in additive manufacturing of gears are given in paper [18]. In paper [18] it is stated: "Additive Layer Manufacturing (ALM) is an advanced technology to produce quality gears of metals and plastics. Some significant benefits such as capability to handle complex gear shapes and design, and produce near net-shaped gears; resource efficiency; and rapid product development etc. make this process a sustainable alternate to the other processes of gear manufacturing". From above papers and literature review, it can be seen that rapid prototyping and additive manufacturing can be used for production of planetary gearbox prototype. It is important to notice that dimensional accuracy of gears manufactured using rapid prototyping will be low. Because of this real gear ratio of two gears will significantly differ from analytical one. Example of toothing accuracy was studied in paper [19]. Polymer gears also have several additional problems. Problem of significant deformation during contact of two gears and problem of significant wear of two gears toots in contact. These problems can also affect the gear ratio [2022]. To solve these problems additional modification of spur gear profile can be carried out [23]. Goal of this paper is to analyse possibilities to use FDM additive manufacturing technology to produce planetary gearbox which can be used for design analysis and for education purposes. Planetary gearbox shown at Fig. 1 is chosen as case study.

\section{ANALYTICAL CALCULATION}

In this chapter, analytical calculation of planetary gearbox, shown on Fig. 1, is presented. More detail calculation procedure can be found in any book which deals with design of planetary gearboxes, good example is book [24].

Initial data:

$n_{1}=2000 \mathrm{~min}^{-1}-$ rpm of gear 1

$n_{3}=-500 \mathrm{~min}^{-1}-$ rpm of gear 3

$i_{13}^{\mathrm{R}}=-3-$ gear ratio between gears 1 and 3 , in regard to

lever R

$P_{1}=25 \mathrm{~kW}-$ power at gear 1

$z_{1}=24-$ number of teeth of gear 1 .

\subsection{Choosing Number of Satellite Gears and Calculation of Number of Gear Teeth for Gears 2 and 3 of Planetary Gearbox}

Equation for gear ratio is given as:

$i_{13}^{\mathrm{R}}=(-1)^{k} \cdot \frac{z_{2} \cdot z_{3}}{z_{1} \cdot z_{2}}$

Where is: $k$ - exponent for number of coupling with external gearing; $z_{2}$ - number of teeth's of gear $2 ; z_{3}$ - number of teeth's of gear 3 .

From Eq. (1) number of teeth of gear 3 can be calculated as:

$z_{3}=-(-3) \cdot z_{1}=72$

Number of teeth of satellite gears 2 can be calculated from the requirement for coaxial characteristic of gears:

$z_{3}=z_{1}+2 z_{2}$

From Eq. (3):

$z_{2}=\frac{z_{3}-z_{1}}{2}=24$

Except for requirement for coaxial characteristic of gears, planetary gearboxes which have more satellite gears 
must fulfil requirements for neighbourhood satellite gears. They must not come in contact during operation. This requirement must be checked using following equation:

$\sin \frac{\pi}{4}>\frac{z_{2}+2}{z_{1}+z_{2}}$

For planetary gearbox shown on Fig. 1, using Eq. (5), following values are calculated and above mentioned requirement is fulfilled:

$0.707>0.54$

The third requirement, which has to be fulfilled, is requirement for checking is it possible to carry out proper assembly of satellite gears. If this requirement isn't fulfilled planetary gearbox will have low dynamic characteristics. Assembly of first satellite gear is always possible, but assembly of other two gears won't be possible if this requirement is not fulfilled during design process. This requirement can be checked using following equation:

$\frac{z_{1}+z_{3}}{K}=$ integer number

Where is: $K=3-$ number of satellite gears, chosen by designer.

For planetary gearbox shown on Fig. 1, using Eq. (7), following values are calculated and above-mentioned requirement is fulfilled:

$\frac{24+72}{3}=32$

\subsection{Calculations of rpm for Gears 2 and 3 and for Lever R of Planetary Gearbox}

Analytical calculations of rpm (revolution per minute) for gears inside planetary gearbox are based on calculation of rpm for regular gears (when relative movement to the lever $\mathrm{R}$ is observed (lever $\mathrm{R}$ is stationary). Gear ratio can be calculated using number of teeth's of that gears, Eq. (9).

$i_{a b}^{\mathrm{R}}=(-1)^{k} \cdot \frac{z_{b}}{z_{a}}=\frac{n_{a}-n_{\mathrm{R}}}{n_{b}-n_{\mathrm{R}}}$

First, calculation of rpm for lever $\mathrm{R}$ needs to be carried out using Eq. (9).

$$
\begin{aligned}
& i_{13}^{\mathrm{R}}=(-1)^{k} \cdot \frac{z_{3}}{z_{1}}=\frac{n_{1}-n_{\mathrm{R}}}{n_{3}-n_{\mathrm{R}}} \\
& n_{\mathrm{R}}=\frac{n_{1}-i_{13}^{\mathrm{R}} \cdot n_{3}}{-i_{13}^{\mathrm{R}}+1}=125 \mathrm{~min}^{-1}
\end{aligned}
$$

Now, calculation of rpm for gear 2 for planetary gearbox shown on Fig. 1, using the same Eq. (9) can be carried out.

$$
\begin{aligned}
& i_{12}^{\mathrm{R}}=(-1)^{k} \cdot \frac{z_{2}}{z_{1}}=\frac{n_{1}-n_{\mathrm{R}}}{n_{2}-n_{\mathrm{R}}} \\
& n_{2}=\frac{n_{1}-n_{\mathrm{R}}+i_{12}^{\mathrm{R}} \cdot n_{\mathrm{R}}}{i_{12}^{\mathrm{R}}}=-1750 \mathrm{~min}^{-1}
\end{aligned}
$$

Where is:

$i_{12}^{\mathrm{R}}=(-1)^{k} \cdot \frac{z_{2}}{z_{1}}=-1-$ gear ratio between gears 1 and 2.

\subsection{Design of Gears for Planetary Gearbox}

First, initial data needs to be selected. Initial data is same for all gears inside of the planetary gearbox and they are chosen by designer with following values:

$m=2 \mathrm{~mm}-$ module

$\beta=0^{\circ}-$ helix angle

$\alpha=\alpha_{\mathrm{n}}=20^{\circ}-$ pressure angle

$\psi=20-$ gear tooth length factor

$z_{1}=24-$ number of teeth of gear 1 .

Diameters and face width of all gears can be calculated according to [25]. Gears 1 and 2 have same dimensions.

Pitch diameter:

$d_{1}=d_{2}=m \cdot z_{1}=48 \mathrm{~mm}$

Addendum diameter:

$d_{\mathrm{a} 1}=d_{\mathrm{a} 2}=d_{1}+2 m=52 \mathrm{~mm}$

Dedendum diameter:

$d_{\mathrm{f} 1}=d_{\mathrm{f} 2}=m \cdot\left(z_{1}-2.4\right)=43.2 \mathrm{~mm}$

Base diameter:

$d_{\mathrm{b} 1}=d_{\mathrm{b} 2}=d_{1} \cdot \cos \alpha=45.1 \mathrm{~mm}$

Face width:

$b_{1}=b_{2}=m \cdot \psi=100 \mathrm{~mm}$

Gears 1, 2 and 3 are shown on Figs. 2, 3 and 4 . Calculation of other machine elements inside planetary gearbox (shafts, bearings, pins etc.) are not presented in this paper because these calculations are too extensive. Those calculations can be found in [24].

Diameters and face width of gear 3 are also calculated.

Pitch diameter:

$d_{3}=m \cdot z_{3}=144 \mathrm{~mm}$ 
Addendum diameter:

$d_{\mathrm{a} 3}=m \cdot\left(z_{3}-2\right)=140 \mathrm{~mm}$

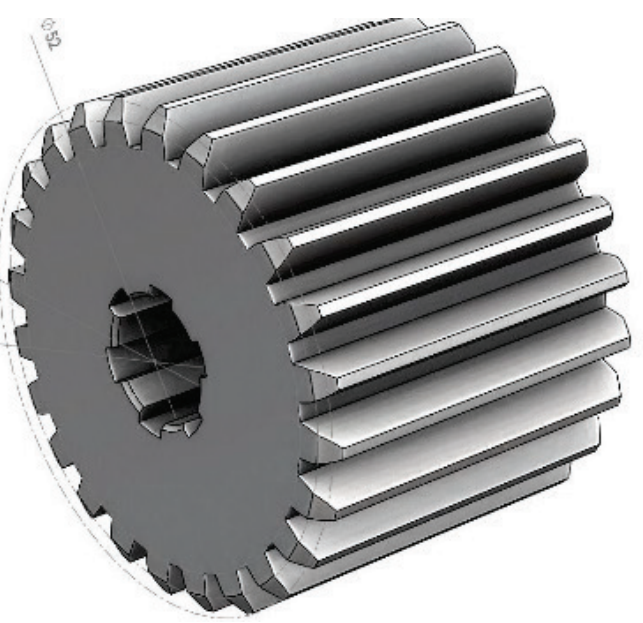

Figure 2 Gear 1

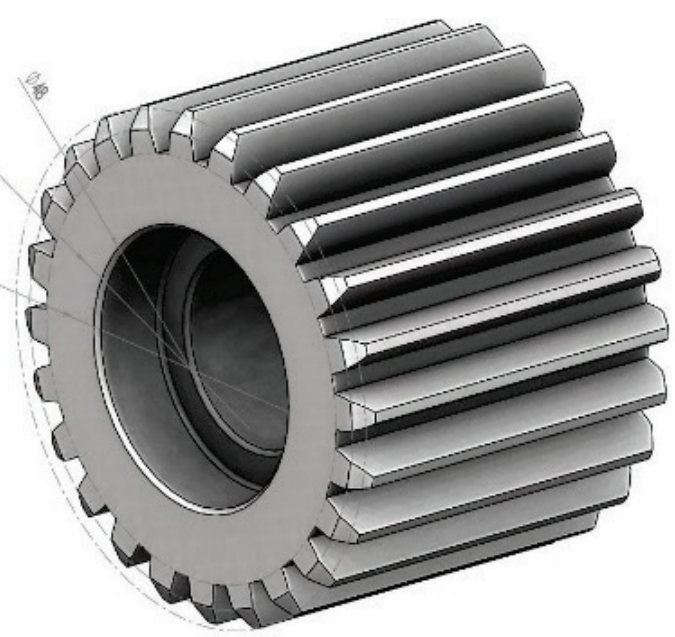

Figure 3 Gear 2

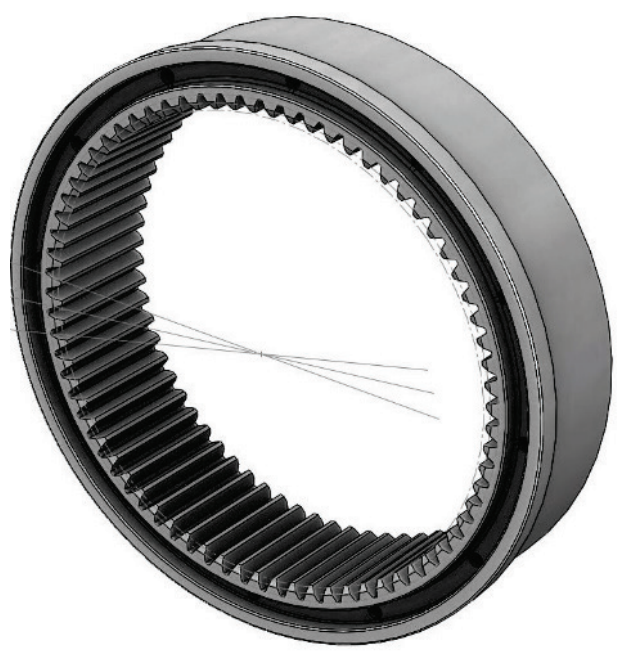

Figure 4 Gear 3
Dedendum diameter:

$d_{\mathrm{f3}}=m \cdot\left(z_{3}+2.4\right)=148.8 \mathrm{~mm}$

Base diameter:

$d_{\mathrm{b} 3}=d_{3} \cdot \cos \alpha=135.32 \mathrm{~mm}$

Face width:

$b_{3}=m \cdot \psi=100 \mathrm{~mm}$

\section{DEVELOPMENT OF CAD MODEL AND MANUFACTURING OF PLANETARY GEARBOX}

Computer aided design (CAD) model is developed according the calculations which are described in previous chapter. CAD models of gears and shafts are developed according to the calculations. Other machine elements like bearings, screws and pins are chosen as standard elements. CAD model of planetary gearbox housing is developed according to the machine where planetary gearbox will be mounted. Inside gears of developed CAD model of planetary gearbox are shown on Fig. 5.

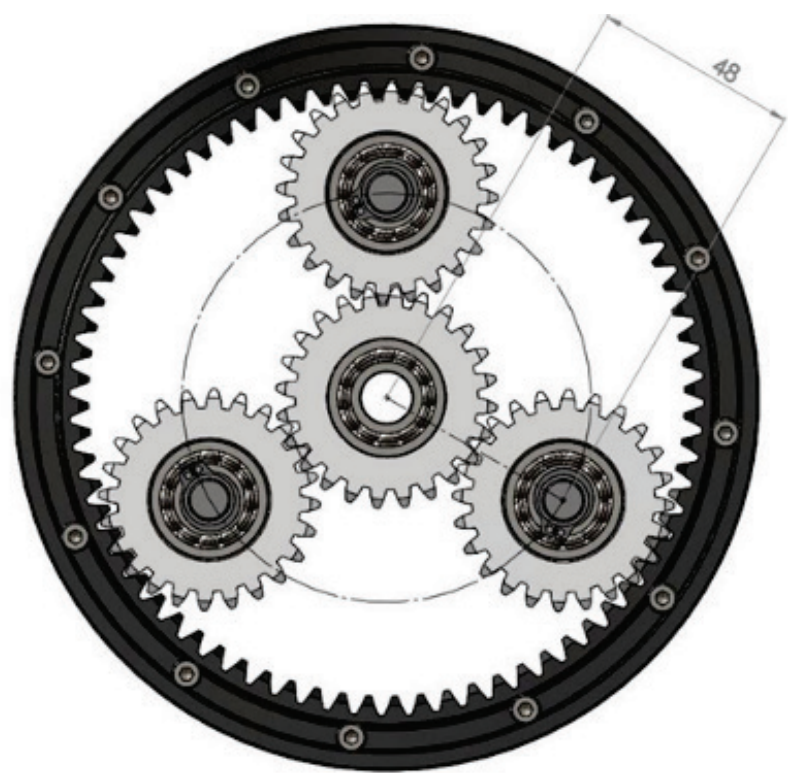

Figure 5 Inside gears of planetary gearbox

Completely developed CAD model of planetary gearbox is shown on Fig. 6. For manufacturing of planetary gearbox fused deposition modelling (FDM) additive manufacturing technology is selected as most affordable technology for rapid prototyping. For manufacturing, different materials are used for different parts of planetary gearbox. Materials like polylactic acid (PLA), polyethylene terephthalate (PET), copolyester (CPE), thermoplastic polyurethane (TPU) and polyamide. Manufactured gears are shown on Fig. 7. Gears 1 and 2 are manufactured by combination of two materials, polyamide (gear teeth's) and PET (gear body). 
Polyamide is chosen for gears teeth's because it has good wear resistance and good mechanical properties. Basically it lubricates itself, similarly like Politetrafluoretilen (PTFE) material. PET is used for inside parts of gears because it has better mechanical properties than polyamide materials.

Because of those mechanical properties, interference fit can be achieved between real metal bearings and gears. Polyamide and PET have similar thermal properties, which is one of the reasons why those two materials can be used together.

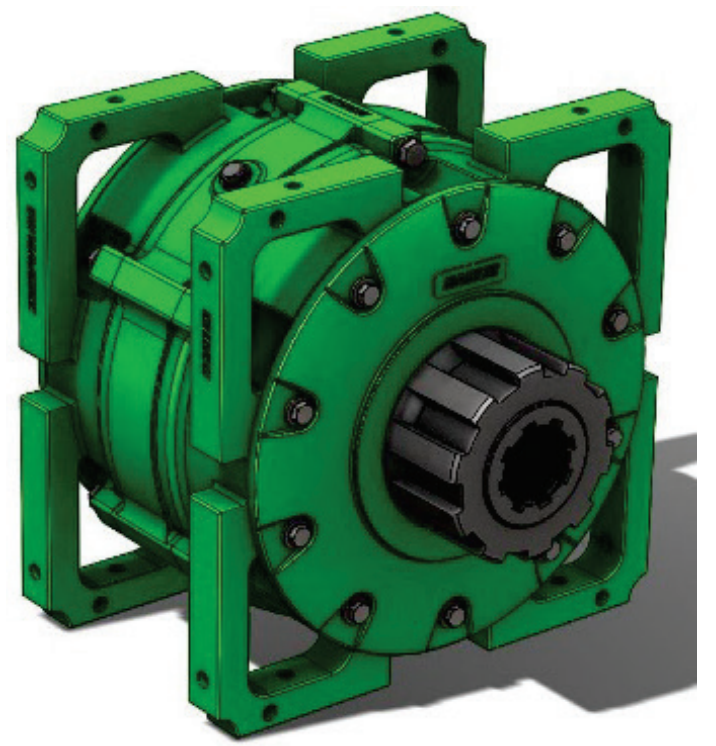

Figure 6 Developed CAD model of planetary gearbox

Gear 3 is manufactured fully from polyamide material. More about different mechanical and thermal properties of materials for additive manufacturing can be found in [26]. Real bearings are used because they are complex machine elements with complex tolerances and fits. They cannot be manufactured using FDM additive manufacturing process if high accuracy is needed, which was the case in the manufacturing process of planetary gearbox. More about tolerances and fits of parts manufactured using additive manufacturing can be found in [27].

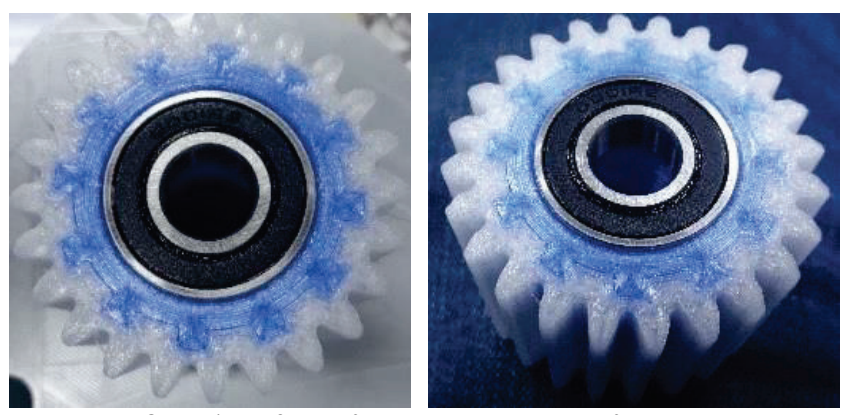

Figure 7 Gears 1 and 2 manufactured by additive manufacturing using two materials

Axles for gears housings are manufactured using $\mathrm{CPE}+$ material because they are the most often loaded parts inside planetary gearbox and $\mathrm{CPE}+$ material has best mechanical properties of all materials available for FDM additive manufacturing up to today (at least to the knowledge of the authors).

Firstly, authors tried to manufacture these axles using PLA material but that axles did not sustain the bending stress loads because stress concentration appear at the places where Seeger rings need to be mounted (Fig. 8).

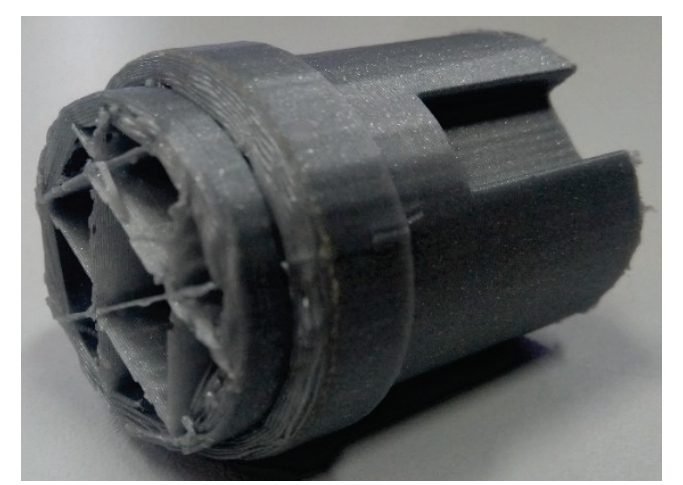

Figure 8 Example of fractured axle manufactured using PLA material

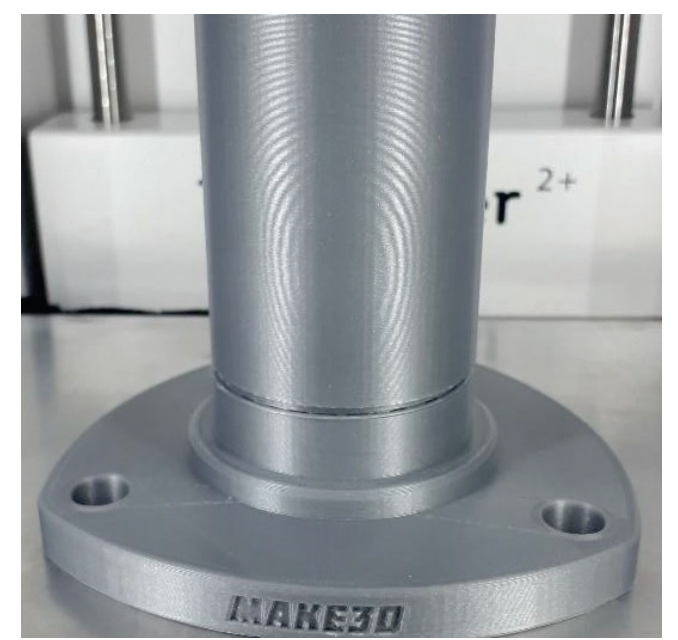

Figure 9 Example of fractured axle manufactured using PLA material

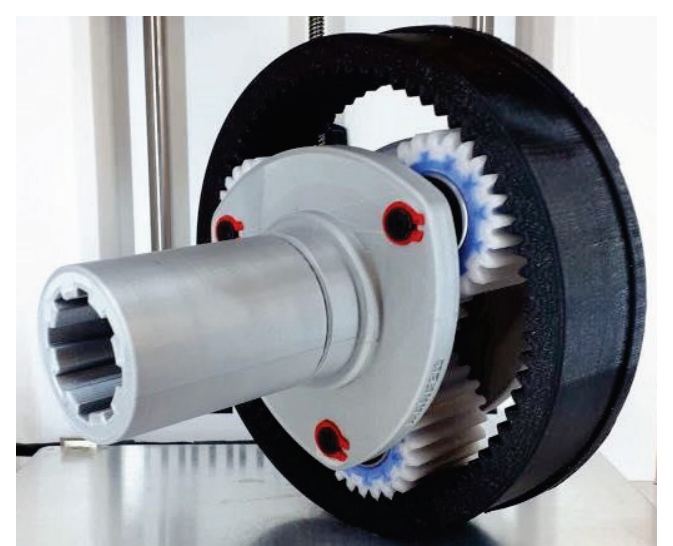

Figure 10 Inside assembly of planetary gearbox

All shafts of planetary gearbox are manufactured using PLA material. Shafts have bigger dimensions and because of that, they can sustain all loads. One of the manufactured shafts are shown at Fig. 9. Seals are manufactured using TPU material. TPU material is additive manufacturing material 
which is most similar to rubber materials. Because of that, it can be used as seal.

Housing of planetary gearbox is manufactured using PLA material, because it is most common material with low price and it can fulfil all requirements in this case.

Inside assembly of planetary gearbox are shown on Fig. 10. Full outside assembly are shown on Fig. 11.

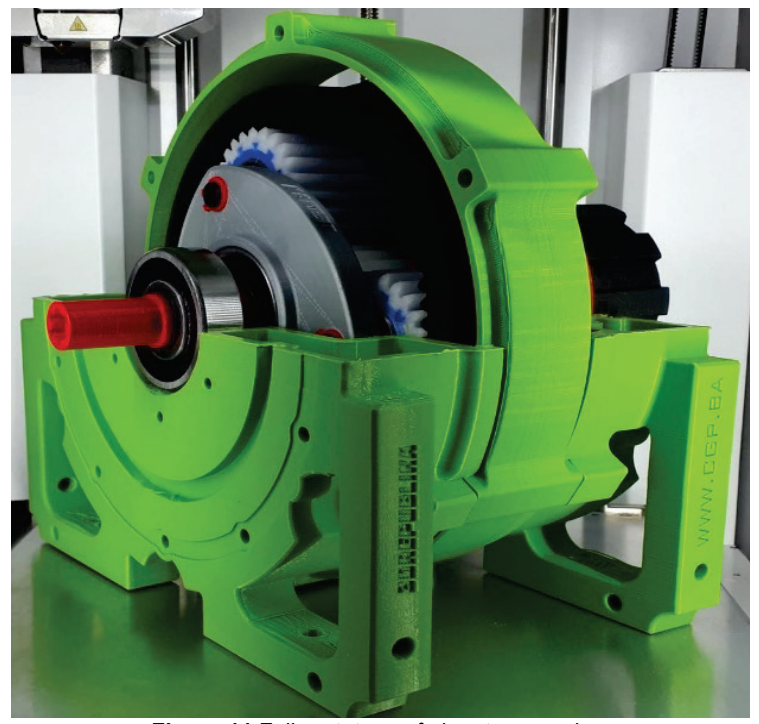

Figure 11 Full prototype of planetary gearbox

\section{ANALYSIS OF ROTATION ACCURACY AND IMPROVEMENT OF EDUCATION}

After manufacturing of planetary gearbox, analysis of rotation accuracy is carried out. Prototype of planetary gearbox is not intended to be fully loaded because those materials cannot sustain full load like steel. To carry out rotation accuracy analysis, gearbox is loaded with $10 \%$ of usually full load, which was enough to measure output rotation speed, calculate measured ratio and compare measured ratio to calculated one by analytical calculation. Results for measured ratio and calculated one are shown in Tab. 1 .

Table 1 Table title aligned centre

\begin{tabular}{|l|c|}
\hline & Ratio \\
\hline Analytical calculation & 4 \\
\hline Measured on prototype & 3.994 \\
\hline Error in \% & $0.15 \%$ \\
\hline
\end{tabular}

Improvement of education is analyzed thought discussion with the students at several courses at mechanical design study program. All students have positive opinion about this type of improvement of education. It is much easier to explain working principles of machines using fully functional prototype in comparison to videos, pictures or drawings. Future research will focus on design and development of other complex machines using low cost rapid prototyping technology.

\section{CONCLUSION}

Design, calculation and manufacturing of planetary gearbox is carried out in this paper. Gears and shafts are designed and calculated. Other machine elements (bearings, screws, pins, etc.) are chosen from standard machine elements. Housing of planetary gearbox is also designed. Full planetary gearbox is manufactured using additive manufacturing as the most affordable rapid prototyping technology (except of standard machine elements). FDM additive manufacturing technology is used.

Goal of the research was to find out is it possible to produce prototype of planetary gearbox which will be used to study the design of all elements of planetary gearbox and to use it in educational purpose at mechanical engineering courses. This type of prototype has low weight, so it can be carried out by professor to the classes. It can be fully disassembled and assembled in front of the students. In addition, it has full functionality like the real planetary gearbox. This paper shows opportunities which additive manufacturing is offering in improvement and innovation of education process at engineering schools and faculties. All complex and heavy machines and machine elements can be manufactured using this type of technology and on that way more precisely presented to the students. It can be concluded that planetary gearbox is successfully developed and manufactured.

\section{REFERENCES}

[1] Wood, J., Campbell, M., Wood, K., \& Jensen, D. (2005). Enhancing the teaching of machine design by creating a basic hands-on environment with mechanical 'breadboards'. International Journal of Mechanical Engineering Education, 33(1), 1-25. https://doi.org/10.7227/JJMEE.33.1.1

[2] Beckmann, G. \& Krause, D. (2010). Improving the mechanical design education by hands-on experience with machine parts. Proceedings of E\&PDE 2010, the $12^{\text {th }}$ International Conference on Engineering and Product Design Education When Design Education and Design Research meet, Trondheim Norway, 592-597.

[3] Beckmann, G. \& Krause, D. (2011). Machine part exhibition and functional mock-ups to enrich design education. International conference on engineering design. Technical University of Denmark, 130-139.

[4] Wood, J., Jensen, D., \& Wood, K. (2005). Enhancing Machine Design Courses through Use of a Multimedia-Based Review of Mechanics of Materials. Proceedings of the 2005 American Society for Engineering Education Annual Conference \& Exposition, American Society for Engineering Education.

[5] Olegovna Gorshkova, O. \& Ivanovich Nekrasov, V. (2018). Planetary gearbox 5R2. International Journal of Mechanical Engineering and Technology, 9(11), 1984-1991.

[6] Gajdosik, T., Brumercik, F., Lukac, M., \& Drozdziel, P. (2018). Vehicle Planetary Gearbox Simulation LOGI. Scientific Journal on Transport and Logistics, 9(1), 11-17. https://doi.org/10.2478/logi-2018-0002

[7] Tianfu, Y. \& Shaoze, Y. (2014). Dynamic Simulation of Planetary Gearbox. Key Engineering Materials, 584, 220-224. https://doi.org/10.4028/www.scetific.net/KEM.584.220 
[8] Ai-Yun, G. \& Zhi-Chao, Z. (2018). Transmission Design and Kinematics Simulation of Fixed Gear and Planetary Gear. IOP Conf. Series: Materials Science and Engineering, 382. https://doi:10.1088/1757-899X/382/4/042008

[9] Yin, H., Li, S., Zhan, H., Zhao, X., \& Zhang, J. (2013). The Power Loss and Efficiency Analysis of a 3DOFs Planetary Gear Box. Advanced Materials Research, 345-836, 1285-1289. https://doi.org/10.4028/www.scientific.net/AMR.834-836.1285

[10] Teixeira Margues, P. M. (2017). Power Loss in Planetary Gearboxes Including the Influence of Gear Elastic and Dynamic Effects, Dissertation, Departamento de Engenharia Mecânica, Faculdade de Engenharia da Universidade do Porto.

[11] Fritz Ploger, D., Zech, P., \& Rinderknecht, S. (2019). Vibration signature analysis of commodity planetary gearboxes. Mechanical Systems and Signal Processing, 119, 255-265. https://doi.org/10.1016/j.ymssp.2018.09.014

[12] Kucera, L., Gejdosik, T., \& Bucala, J. (2014). The Vibrodiagnostics of Damaged Gears of Planetary Gearboxes. Comunications, 16(3), 67-73.

[13] Mahindru, D. V. \& Mahendru, P. (2013). Review of Rapid Prototyping-Technology for the Future. Global Journal of Computer Science and Technology Graphics \& Vision, 13(4), 28-37.

[14] Wong, V. K. \& Hernandez, A. (2012). A Review of Additive Manufacturing. International Scholarly Research Network ISRN Mechanical Engineering. https://doi.org/10.5402/2012/208760

[15] Muminovic, A.J. Colic, M, Mesic, E., \& Saric, I. (2020). Innovative design of spur gear tooth with infill structure. Bulletin of the polish academy of sciences, technical sciences, 68(3), 477-483. https://doi.org/10.24425/bpasts.2020.133370

[16] Mitrovic, R., Miskovic, Z., Ristivojevic, M., Dimic, A., Danko, J., Bucha, J., \& Rackov, M. (2018). Determination of optimal parameters for rapid prototyping of the involute gears. IOP Conf. Series: Materials Science and Engineering, 393. https://doi.org/10.1088/1757-899X/393/1/012105

[17] Oleksy, M., Budzik, G., \& Heneczkowski, M. (2010). Hybrid polymer composites for rapid prototyping of gears. Polimery, 55(5). https://doi.org/10.14314/polimery.2010.403

[18] Gupta, K. (2018). Recent Developments in Additive Manufacturing of Gears: A Review. Advanced in Manufacturing Technology. IOS Press.

[19] Nieszporek, T., Gołębski, R., \& Šooš, L. (2017). Analysis of the wormwheel toothing accuracy. Tehnički vjesnik, 24(4), 993-1000. https://doi.org/10.17559/TV-20160422094400

[20] Kowalik, M., Rucki, M., Paszta, P., \& Gołębski, R. (2016). Plastic Deformations of Measured Object Surface in Contact with Undeformable Surface of Measuring Tool. Measurement science review 16(5), 254-259. https://doi.org/10.1515/msr-2016-0031

[21] Gołębski, R. \& Szarek, A. (2019). Diagnosis of the Operational Gear Wheel Wear. Tehnički vjesnik, 26(3), 658-661. https://doi.org/10.17559/TV-20180321171428

[22] Gnatowski, A., Gołębski, R., \& Sikora, P. (2021). Analysis of the Impact of Changes in Thermomechanical Properties of Polymer Materials on the Machining Process of Gears. Polymers, 13(1), 13-28. https://doi.org/10.3390/polym13010028

[23] Gołębski, R. and Ivandić, Z. (2018). Analysis of Modification of Spur Gear Profile. Tehnički vjesnik, 25(2), 643-648. https://doi.org/10.17559/TV-20171018100732

[24] Zorowski, C. F. (2016). Design of Mechanical Power Transmissions, Design Engineering Monographs, Volume 1, CreateSpace Independent Publishing Platform; 1 edition. Scotts Valley, California, SAD.
[25] Budynas, R. G. (2014) Shigley's Mechanical Engineering Design McGraw-Hill Education; 10 edition. New York, NY.

[26] Dizon, C. J. R., Espera, Jr, A. H., Chen, Q., \& Advincula, R. C. (2018). Mechanical characterization of 3D-printed polymers. Additive Manufacturing, 20, 44-67. https://doi.org/10.1016/j.addma.2017.12.002

[27] Lieneke, T., Denzer, V., Adam, G. A. O., \& Zimmer, D. (2016). Dimensional tolerances for additive manufacturing: Experimental investigation for Fused Deposition Modeling. Procedia CIRP, 43, 286-291. https://doi.org/10.1016/j.procir.2016.02.361

\author{
Authors' contacts: \\ Jasmin Smajic, MSc \\ University of Sarajevo, Faculty of Mechanical Engineering, \\ Sarajevo, Bosnia and Herzegovina \\ Tel.: +387 33729800 \\ jasmin@protodevs.com \\ Isad Saric, Associate Professor \\ University of Sarajevo, Faculty of Mechanical Engineering, \\ Vilsonovo šetalište 9, 71000 Sarajevo, Bosnia and Herzegovina \\ Tel.: +38733729 800 \\ saric@mef.unsa.ba \\ Adil Muminovic, Full Professor \\ University of Sarajevo, Faculty of Mechanical Engineering, \\ Vilsonovo šetalište 9,71000 Sarajevo, Bosnia and Herzegovina \\ Tel.: +38733729 800 \\ muminovic@mef.unsa.ba
}

Muamer Delic, Senior research assistant

University of Sarajevo, Faculty of Mechanical Engineering,

Vilsonovo šetalište 9, 71000 Sarajevo, Bosnia and Herzegovina

Tel.: +38733729 800

delic@mef.unsa.ba

Adis J. Muminovic, Assistant Professor

(Corresponding author)

University of Sarajevo, Faculty of Mechanical Engineering,

Vilsonovo šetalište 9, 71000 Sarajevo, Bosnia and Herzegovina

Tel.: +38733729 800

adis.muminovic@mef.unsa.ba 